\title{
PENGARUH MODAL DAN SKILL TERHADAP MINAT MAHASISWA MENJADI ENTREPRENEUR (STUDI PADA MAHASISWA JURUSAN EKONOMI SYARIAH IAIN PADANGSIDIMPUAN)
}

\author{
Nur Husnah Hasibuan ${ }^{1}$, Darwis Harahap ${ }^{2}$, Azwar Hamid ${ }^{3}$ \\ ${ }^{1}$ Mahasiswa IAIN Padangsidimpuan \\ 2,3 Dosen IAIN Padangsidimpuan \\ Email: darwisharahap05@yahoo.com
}

\begin{abstract}
The background of this study is a phenomenon that occurs in students of the Islamic Economics Department of the Padangsidimpuan State Islamic Institute who have an interest in becoming an entrepreneur / entrepreneur. The formulation of the problem in this study is whether there is an influence of capital and skills on students' interest in becoming entrepreneurs. This study aims to determine the effect of capital and skills on students' interest in becoming entrepreneurs. The usefulness of this research is to increase knowledge in the field of entrepreneurship, as an input to becoming more advanced and motivated entrepreneurs to increase students' interest in becoming entrepreneurs. This study discusses the theories relating to entrepreneurship science, namely the theoretical approach regarding students' interest in becoming entrepreneurs who are influenced by capital and skill factors. This research was conducted in February 2017 in the Department of Islamic Economics, Faculty of Economics and Business, Islamic State Institute of Padangsidimpuan. This type of research is quantitative research. The population in this study were students of the Islamic Economics Department from 2013 to 2015. The samples in this study were 88 respondents. Data sources were obtained from primary data with data collection techniques, namely distributing questionnaires to students of the Department of Islamic Economics from 2013 to 2015 at random. Test instruments using validity and reliability tests. The analytical method used is multiple linear regression analysis, descriptive analysis, normality test, linearity test, multicollinearity test and heterocedasticity test. Testing the hypothesis used is a statistical test simultaneously (F test) and a statistical test partially ( $t$ test) with a significant level of $\alpha=10 \%$. The test results with multiple linear regression analysis obtained $M E$ equation $=9,249+0,253 M$ $+0,444 S$. Simultaneous test results obtained Fcount $=29,887>$ Ftable $=2,366$ with a significant level of 0,000<0,1 this can be concluded that capital and skills have a significant effect on students' interest in becoming entrepreneurs. Partial test results obtained tcount $>$ Ttable $=3.483>1.663$ which indicates that there is an influence of capital towards students 'interest in becoming entrepreneurs and there is influence of skills on students' interest in becoming entrepreneurs with partial test results obtained tcount $>$ ttable $=4.541>1.663$.
\end{abstract}

Keywords: Capital, Skill, Interest in becoming an Entrepreneur 


\section{PENDAHULUAN}

Entrepreneurship merupakan perilaku dinamik, menerima risiko, kreatif serta yang berorientasi pada pertumbuhan. ${ }^{1}$ Secara sederhana arti wirausahawan (entrepreneur) adalah orang yang berjiwa berani mengambil risiko untuk membuka usaha dalam berbagai kesempatan. Berjiwa berani mengambil risiko artinya bermental mandiri dan berani memulai usaha, tanpa diliputi rasa takut atau cemas sekalipun dalam kondisi tidak pasti. Kegiatan wirausaha dapat dilakukan seorang diri atau berkelompok. Seorang wirausahawan dalam pikirannya selalu berusaha mencari, memanfaatkan serta menciptakan peluang usaha yang dapat memberikan keuntungan. ${ }^{2}$

Oleh karena itu, budaya kewirausahaan yang tumbuh secara alami dalam suatu keluarga atau kelompok masyarakat merupakan suatu aset yang sangat berharga bagi suatu bangsa, dan dinamika perekonomian bangsa yang bertumpu pada pertumbuhan budaya kewirausahaan tradisional ini, perlu diberikan motivasi dalam suatu kegiatan pendidikan khususnya di perguruan tinggi secara umum, yaitu kegiatan program pengembangan kewirausahaan yang dapat memberikan motivasi untuk menumbuhkembangkan budaya kewirausahaan di lingkungan perguruan tinggi untuk mendorong terciptanya entrepreneur baru dengan menerapkan ilmu yang dipelajari dalam berwirausaha.

Entrepreneur adalah seseorang yang menciptakan sebuah bisnis baru, dengan menghadapi risiko dan ketidakpastian, yang bertujuan untuk mencapai laba serta pertumbuhan melalui pengidentifikasian peluang-peluang melalui kombinasi sumber-sumber daya yang diperlukan untuk mendapatkan manfaatnya. ${ }^{3}$ Jadi, entrepreneur perlu diperhatikan dan ditumbuhkembangkan melalui dunia pendidikan, dengan pembekalan dan penanaman jiwa entrepreneur pada mahasiswa akan memotivasi mahasiswa untuk lebih giat melakukan kegiatan wirausaha. Pengalaman yang diperoleh di bangku kuliah,

${ }^{1}$ J. Winardi, Entrepreneur \& Entrepreneurship (Jakarta: Kencana, 2003), hlm. 16.

${ }^{2}$ Kasmir, Kewirausahaan (Jakarta: Rajawali Pers, 2013), hlm. 19-20.

${ }^{3}$ J. Winardi, Op. Cit., hlm. 17. 
khususnya melalui mata kuliah Kewirausahaan diharapkan bisa dilanjutkan setelah lulus, sehingga akan muncul entrepreneur baru yang berhasil menciptakan lapangan kerja, sekaligus menyerap tenaga kerja.

Seorang entrepreneur berarti telah menjadi seorang pebisnis. Menjadi pebisnis merupakan aset bangsa, karena mereka akan memberikan kontribusi positif pada pertumbuhan ekonomi negara. Setiap pebisnis umumnya memiliki karakteristik yang sama, seperti keinginan berprestasi, keinginan untuk bertanggung jawab, berani mengambil risiko, keyakinan untuk berhasil, energik, berorientasi ke masa depan, jiwa kepemimpinan yang menonjol, tekun dan pekerja keras. ${ }^{4}$ Oleh karena itu, kewirausahaan dapat dikatakan sebagai salah satu faktor penentu bagi kemajuan suatu negara dan pertumbuhan ekonomi dapat dicapai jika negara memiliki banyak wirausaha.

Peningkatan jumlah entrerpreneur dengan melakukan survei di bulan Februari 2014, jumlah wirausahawan (entrepreneur) mencapai 44,20 juta orang dari 118,17 juta orang penduduk Indonesia yang bekerja. ${ }^{5}$ Oleh karena itu, minat seseorang untuk menjadi entrepreneur masih sangat rendah.

Berdasarkan ungkapan di atas, minat berwirausaha perlu ditingkatkan dalam diri seseorang agar pertumbuhan ekonomi semakin baik ke depannya, khususnya bagi mahasiswa yang memiliki kemampuan dalam menemukan dan menciptakan berbagai ide kreatif dan inovatif, karena setiap pikiran dan langkah wirausahawan adalah bisnis. Bahkan, mimpi seorang pebisnis sudah merupakan ide untuk berkreasi dalam menemukan dan menciptakan bisnisbisnis baru.

Pemahaman tentang bisnis telah diajarkan oleh dosen atau tenaga pendidik di Jurusan Ekonomi Syariah Institut Agama Islam Negeri (IAIN) Padangsidimpuan, melalui teori mata kuliah Kewirausahaan dan praktikum secara langsung dengan mengadakan kegiatan Entrepreneurship Day`s bersama mahasiswa IAIN Padangsidimpuan, karena Fakultas Ekonomi dan

\footnotetext{
${ }^{4}$ Netti Tinaprilla, Jadi Kaya dengan Berbisnis di Rumah (Jakarta: PT. Elex Media Komputindo, 2007), hlm. 57.

${ }^{5}$ http://www.republika.co.id, di akses pada hari Senin tanggal 21 Maret 2017 pukul 16.00 WIB.
} 
Bisnis Islam (FEBI) IAIN Padangsidimpuan memiliki visi dan misi yaitu: "Menjadikan Fakultas Ekonomi dan Bisnis Islam Centre of Exellence untuk menghasilkan lulusan yang profesional, entrepreneurship dan berakhlak mulia di Sumatera Utara Tahun 2025, serta menanamkan jiwa entrepreneurship yang inovatif dan kreatif untuk menciptakan lapangan kerja". 6

Jumlah mahasiswa FEBI IAIN Padangsidimpuan, mahasiswa Jurusan Ekonomi Syariah dalam bidang Ilmu Ekonomi, Manajemen Bisnis dan Akuntansi sebagian besar telah berkecimpung di dunia entrepreneur (wirausaha), ada mahasiswa yang berbisnis kecil-kecilan seperti: jualan gorengan, jualan pulsa, bahkan sampai ke bisnis online. Namun ada juga mahasiswa yang minat berwirausaha, namun memiliki keterbatasan dalam segi finansial, tetapi pada dasarnya mahasiswa tersebut memiliki kemampuan dan keterampilan dalam menciptakan ide kreatif dan inovatif untuk memulai usaha baru serta menciptakan lapangan kerja. Fakultas Ekonomi dan Bisnis Islam memiliki 1415 mahasiswa. ${ }^{7}$ Peneliti hanya fokus pada mahasiswa Jurusan Ekonomi Syariah Angkatan 2013 sampai dengan 2015 yaitu sejumlah 700 mahasiswa yang akan diambil sebagai sampel sebanyak 88 mahasiswa dari jumlah tersebut.

Peneliti memperoleh informasi bahwa tidak lebih dari 50\% mahasiswa untuk setiap ruangan yang memiliki wirausaha. Pernyataan ini diperkuat dari survei yang telah dilakukan peneliti dengan membagikan kuesioner pada mahasiswa Jurusan Ekonomi Syariah semester IV, semester VI, dan semester VIII dengan jumlah sampel 88 orang. Berikut hasil survei yang dilakukan peneliti:

\section{Tabel 1.1}

\section{Data Aktivitas Mahasiswa Jurusan Ekonomi Syariah Fakultas Ekonomi dan Bisnis Islam IAIN Padangsidimpuan}

${ }^{6}$ Buku Pedoman MagangJurusan Ekonomi Syariah dan Jurusan Perbankan Syariah, Visi dan Misi Fakultas Ekonomi dan Bisnis Islam (Padangsidimpuan: FEBI IAIN Padangsidimpuan, 2016), hlm. 2.

${ }^{7}$ Data Akademik Jurusan Ekonomi Syariah Fakultas Ekonomi dan Bisnis Islam IAIN Padangsidimpuan 


\begin{tabular}{|l|c|c|}
\hline \multicolumn{1}{|c|}{ Kriteria } & $\begin{array}{c}\text { Jumlah } \\
\text { (Orang Mahasiswa) }\end{array}$ & Persentase \\
\hline Berwirausaha & 39 & $44,32 \%$ \\
\hline Tidak Berwirausaha & 49 & $55,68 \%$ \\
\hline Total & 88 & $100 \%$ \\
\hline
\end{tabular}

Sumber: Data Primer diolah dari jawaban responden pada hasil angket, 2017

Berdasarkan tabel di atas, peneliti berasumsi bahwa minat mahasiswa masih kurang untuk menjadi wirausaha/entrepreneur, sedangkan Agama Islam menekankan kepada manusia untuk bekerja dengan tangan sendiri, karena itu lebih baik daripada meminta-minta. Berdasarkan uraian latar belakang di atas, maka tujuan dari penelitian ini adalah: untuk mengetahui pengaruh modal terhadap minat mahasiswa menjadi entrepreneur pada mahasiswa Jurusan Ekonomi Syariah IAIN Padangsidimpuan, untuk mengetahui pengaruh skill terhadap minat mahasiswa menjadi entrepreneur pada mahasiswa Jurusan Ekonomi Syariah IAIN Padangsidimpuan, untuk mengetahui pengaruh modal dan skill terhadap minat mahasiswa menjadi entrepreneur pada mahasiswa Jurusan Ekonomi Syariah IAIN Padangsidimpuan.

\section{KAJIAN TEORITIS}

Semakin maju suatu Negara semakin banyak orang yang terdidik, dan banyak pula orang yang menganggur, maka semakin dirasakan pentingnya dunia wirausaha. Pembangunan akan lebih berhasil jika ditunjang oleh wirausahawan yang dapat membuka lapangan kerja karena kemampuan pemerintah sangat terbatas. ${ }^{8}$ Berarti dalam mewujudkan Negara yang maju, masyarakat perlu meningkatkan minatnya dalam dunia wirausaha agar dapat menciptakan pekerjaan bagi orang yang menganggur. Menurut Kamus Besar Bahasa Indonesia, minat merupakan perhatian, kesukaan, dan kecenderungan hati. ${ }^{9}$ Maka minat diartikan sebagai suatu perasaan, keinginan dan dorongan bagi seseorang untuk melakukan sesuatu yang merupakan kecenderungan

${ }^{8}$ Buchari Alma, Kewirausahaan (Bandung: Alfabeta, 2009), hlm. 1.

${ }^{9}$ Desi Anwar, Kamus Lengkap Bahasa Indonesia (Surabaya: Amelia, 2003), hlm. 281. 
hati/kesukaan melalui pernyataan atau tindakan, yang dilakukan tanpa ada paksaan.

Entrepreneur berasal dari bahasa Perancis yang merupakan istilah dari wirausaha. Entrepreneur merupakan orang yang menanggung risiko berbeda dengan orang yang memberi modal. ${ }^{10}$ Artinya individu akan merasa tertantang untuk menciptakan kerja bukan untuk mencari kerja, karena ekonomi suatu bangsa akan meningkat ketika minat entrepreneurship masyarakat semakin tinggi. Realitas semacam ini menjadi perhatian bagi peneliti sebagai salah satu masyarakat yang sadar akan peran penting dari menanamkan minat entrepreneurship sejak dini.

Entrepreneur diartikan sebagai orang-orang yang merasakan adanya peluang, mengejar peluang yang cocok dengan dirinya dan percaya bahwa keberhasilan merupakan sesuatu yang bisa dicapai, pengertian ini menonjolkan kepekaan dan kemampuan seorang entrepreneur memilih usaha yang cocok dan sesuai dengan minat serta kemampuannya, yang sejalan dengan ilmu yang dikuasainya juga.

Entrepreneur bukanlah orang-orang yang memilih usaha di segala bidang, melainkan mereka mempelajari, mengamati, mencari informasi dari data-data yang ingin mereka ketahui, lalu bergerak dengan intuisi serta pengetahuannya untuk membangun sebuah usaha. Para ahli mengemukakan bahwa seseorang memiliki minat untuk menjadi wirausaha disebabkan karena adanya suatu motif, yaitu motif berprestasi, yang merupakan suatu nilai sosial yang menekankan pada hasrat untuk mencapai hasil terbaik guna mencapai kepuasan pribadi. ${ }^{11}$

Berarti jiwa kewirausahaan akan mendorong minat seseorang untuk mendirikan dan mengelola usaha secara profesional. Hendaknya minat tersebut diikuti dengan perencanaan dan perhitungan yang matang. Misalnya dalam hal memilih atau menyeleksi bidang usaha yang akan dijalankan sesuai dengan kemampuan entrepreneur. Pemilihan bidang usaha seharusnya disertai dengan

\footnotetext{
${ }^{10}$ Buchari Alma, Op. Cit., hlm. 22-23.

${ }^{11}$ Suryana, Kewirausahaan (Jakarta: Salemba Empat, 2010), hlm. 52.
} 
berbagai pertimbangan seperti minat, modal, kemampuan dan pengalaman sebelumnya. Jika belum memiliki pengalaman sebelumnya, seseorang dapat menimba pengalaman dari orang lain.

Adapun alasan-alasan seseorang tertarik untuk menjadi wirausaha adalah $:^{12}$

1) Alasan keuangan, untuk mencari nafkah, menjadi kaya, dan memiliki pendapatan tambahan.

2) Untuk memperoleh status agar dapat dikenal, dihormati dan bertemu orang banyak.

3) Untuk memberikan pekerjaan kepada masyarakat yang membutuhkan.

4) Untuk menjadi mandiri, lebih produktif dan dapat menggunakan kemampuan pribadi.

Karakteristik dari wirausahawan/ entrepreneur, yaitu: ${ }^{13}$

1) Entrepreneur adalah pelaku, bukan pemikir

2) Entrepreneur dilahirkan, bukan dibuat atau diciptakan

3) Entrepreneur selalu menjadi penemu atau pencipta sesuatu

4) Entrepreneur adalah akademisi, dan sulit menyesuaikan dengan masyarakat

5) Entrepreneur menginginkan keberhasilan, tetapi pengalaman menyatakan tingkat kegagalan cukup tinggi.

Islam menekankan bahwa keberadaan manusia di dunia adalah untuk mengabdikan diri kepada Allah SWT. Bagi seorang muslim, menjalankan usaha merupakan aktivitas ibadah sehingga ia harus dimulai dengan niat yang suci, cara yang benar, dan tujuan serta pemanfaatan hasil secara benar. Sebab, dengan itulah ia memperoleh garansi keberhasilan dari Tuhan. ${ }^{14}$ Jadi, wirausahawan muslim harus menyadari bahwa status atau

${ }^{12}$ Suryana, Kewirausahaan: Kiat dan Proses Menuju Sukses (Jakarta: Salemba Empat, 2013), hlm. 52-53.

${ }^{13}$ Muh. Yunus, Islam dan Kewirausahaan Inovatif (Malang: UIN-Malang Press, 2008), hlm. 32-34.

${ }^{14}$ Ibid., hlm. 55-56. 
profesinya adalah amanah. Oleh karena itu, keberadaannya dalam tugas dan jabatan apapun selalu digunakan untuk mencapai penunaian amanah tersebut.Allah SWT berfirman dalam QS. Al-Anfâl: 27 sebagai berikut:

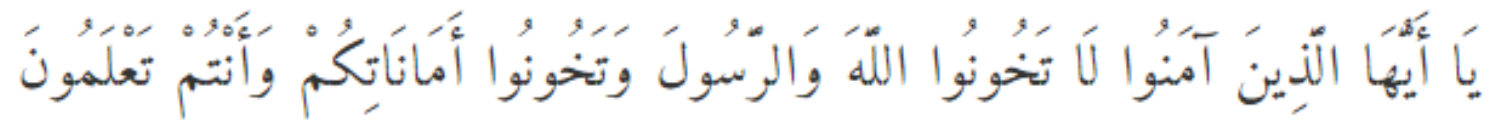

Hai orang-orang yang beriman, janganlah kamu mengkhianati Allah dan

Rasul (Muhammad) dan (juga) janganlah kamu mengkhianati amanatamanat yang dipercayakan kepadamu, sedang kamu mengetahui. ${ }^{15}$

Ketika syariah membolehkan setiap muslim memiliki harta benda yang baik dan yang diinginkannya, syariah menentukan dalam mencapai harta benda tersebut harus dilakukan dengan cara yang disyariatkan dan agar menghindarkan diri dari cara-cara yang haram walaupun cara itu bisa menghasilkan harta yang halal.16 Namun demikian sebagai wirausaha muslim perlu juga memiliki etika berwirausaha. Adapun ketentuan yang diatur dalam etika wirausaha secara umum, yaitu: ${ }^{17}$

1) Sikap dan perilaku seorang pengusaha harus mengikuti norma yang berlaku dalam suatu Negara atau masyarakat

2) Penampilan yang ditunjukkan seorang pengusaha harus selalu baik, sopan, terutama dalam menghadapi situasi atau acara-acara tertentu

3) Cara berpakaian pengusaha juga harus sopan dan sesuai dengan tempat dan waktu yang berlaku

4) Cara berbicara seorang pengusaha juga mencerminkan usahanya, sopan, penuh tata krama, tidak menyinggung atau mencela orang lain

5) Gerak-gerik seorang pengusaha juga dapat menyenangkan orang lain, hindarkan gerak-gerik yang dapat mencurigakan.

Sikap dan perilaku seorang entrepreneur sangat berpengaruh dalam menjalankan, meningkatkan, dan mengembangkan usaha yang

${ }^{15}$ Departemen Agama RI, Al-Qur`an dan Terjemahnya (Semarang: PT. Karya Toha Putra, 1999), hlm. 143.

${ }^{16}$ Abdullah Li Am Ibnu Ibrahim, Konglomerat Sukses: Bagaimana Meraih dan Mengelola Kekayaan Menurut Tuntunan Islam (Jakarta: Zikrul Hakim, 2004), hlm. 55.

${ }^{17}$ Kasmir, Kewirausahaan (Jakarta: Rajawali Pers, 2013), hlm. 24-25. 
dilakukannya. Sementara itu, indicator dari minat berwirausaha ada bermacam-macam, diantaranya: ${ }^{18}$

1) Kemauan keras untuk mencapai tujuan dan kebutuhan hidup

Seorang wirausaha tidak akan berhasil apabila tidak memiliki pengetahuan, kemampuan dan kemauan. Jadi, wirausahawan harus memiliki kemauan yang keras untuk mencapai tujuan agar mampu memenuhi kebutuhan dalam hidupnya.

2) Ketahanan fisik dan mental

Modal mental adalah kesiapan mental berdasarkan landasan agama, diwujudkan dalam bentuk keberanian untuk menghadapi risiko dan tantangan, serta memiliki kepercayaan diri yang kuat, ketidaktergantungan terhadap orang lain dan indivualistis.

3) Sikap jujur dan tanggung jawab

Perilaku seorang wirausahawan dalam syariat Islam harus memenuhi sifat-sifat Rasulullah SAW, yaitu jujur. Ide dan perilaku seorang wirausaha tidak terlepas dari tuntutan tanggung jawab. Oleh karena itulah komitmen sangat diperlakukan dalam pekerjaan sehingga mampu melahirkan tanggung jawab.

\section{METODE PENELITIAN}

Peneliti melakukan penelitian terhadap Mahasiswa Angkatan 2013 sampai dengan 2015 Jurusan Ekonomi Syariah Fakultas Ekonomi dan Bisnis Islam Institut Agama Islam Negeri Padangsidimpuan yang berada di Jln.H.T.Rizal Nurdin, Km.4,5 Padangsidimpuan, Sumatera Utara. Peneliti melakukan penelitian terhadap mahasiswa Angkatan 2013 sampai dengan 2015 karena mahasiswa tersebut telah memenuhi kriteria dan telah melalui mata kuliah Kewirausahaan, dan hanya Jurusan Ekonomi Syariah yang diteliti

\footnotetext{
${ }^{18}$ Suryana, Op. Cit., hlm. 33.
} 
karena keterbatasan peneliti. Penelitian ini dilaksanakan mulai dari bulan Februari sampai dengan bulan April 2017.

Jenis Penelitian yang dilakukan pada penelitian ini adalah penelitian kuantitatif. Penelitian kuantitatif adalah penelitian yang bekerja dengan angka, yang datanya berwujud bilangan, dan dianalisis menggunakan statistik untuk menjawab pertanyaan atau hipotesis penelitian yang bersifat spesifik, dan untuk melakukan prediksi bahwa suatu variabel mempengaruhi variabel yang lain. ${ }^{19}$ Jadi, data diperoleh peneliti dari hasil angket (kuesioner) yang akan diolah melalui Statistical Product and Service Solutions (SPSS).

Populasi dari penelitian ini adalah Mahasiswa Jurusan Ekonomi Syariah Fakultas Ekonomi dan Bisnis Islam Institut Agama Islam Negeri Padangsidimpuan mulai dari Tahun Akademik 2013/2014 sampai dengan Tahun Akademik 2015/2016, yaitu sejumlah 700 mahasiswa. Jumlah ini diperoleh dari data akademik Jurusan Ekonomi Syariah, dengan data sebagai berikut:

Tabel 3.1

Data Mahasiswa Jurusan Ekonomi Syariah

\begin{tabular}{|c|c|c|}
\hline \multirow{2}{*}{ Tahun Akademik } & \multicolumn{2}{|c|}{ Jumlah Mahasiswa } \\
\cline { 2 - 3 } & Laki-Laki & Perempuan \\
\hline $2013 / 2014$ & 52 & 179 \\
\hline $2014 / 2015$ & 65 & 170 \\
\hline $2015 / 2016$ & 60 & 174 \\
\hline Total & 177 & 523 \\
\hline \multicolumn{2}{|c|}{ Total keseluruhan 700 orang } \\
\hline
\end{tabular}

Sumber: Data Akademik Jurusan Ekonomi Syariah

Fakultas Ekonomi dan Bisnis Islam

IAIN Padangsidimpuan

Sampel penelitian ini diambil dari sebagian populasi yang telah ditentukan, yaitu sebagian Mahasiswa Jurusan Ekonomi Syariah Fakultas

\footnotetext{
${ }^{19}$ Asmadi Alsa, Pendekatan Kuantitatif \& Kualitatif Serta Kombinasinya Dalam Penelitian Psikologi (Yogyakarta: Pustaka Pelajar, 2004), hlm. 13.
} 
Ekonomi dan Bisnis Islam Institut Agama Islam Negeri Padangsidimpuan yang masih aktif selama penelitian ini berlangsung.

Untuk mengetahui jumlah sampel yang akan diambil oleh peneliti untuk melakukan penelitian ini, maka peneliti menggunakan rumus slovin, yaitu: ${ }^{20}$

$\mathrm{n}=\frac{N}{1+N e^{2}}$

Dimana:

$\mathrm{n}=$ ukuran sampel

$\mathrm{N}=$ ukuran populasi

$\mathrm{e}=$ kesalahan yang diterima $10 \%(0,1)$

Maka, $\mathrm{n}=\frac{700}{1+700(0,1)^{2}}=87,5$ dibulatkan menjadi 88 orang mahasiswa

Instrumen dan teknik pengumpulan data yang digunakan yaitu:

1. Angket (kuesioner) merupakan suatu pengumpulan data dengan memberikan atau menyebarkan daftar pertanyaan/pernyataan kepada responden dengan harapan memberikan respon atas daftar pertanyaan tersebut. $^{21}$

2. Dokumentasi merupakan cara yang dilakukan peneliti dalam pengumpulan bukti dan keterangan penelitian seperti gambar, kutipan, guntingan koran dan bahan referensi lain.

3. Observasi merupakan teknik yang menuntut adanya pengamatan dari si peneliti baik secara langsung ataupun tidak langsung terhadap objek penelitiannya. $^{22}$

Analisis data dilakukan dengan terlebih dahulu melakukan uji validitas dan reliabilitas. Selanjutnya dilakukan analisis deskriptif, uji normalitas, uji linearitas, uji asumsi klasik (uji multikolinearitas dan uji heteroskedastisitas. Selanjutnya dilakukan analisis terhadap koefisien determinasi ( $R$-squared).

${ }^{20}$ Husein Umar, Metode Penelitian untuk Skripsi dan Tesis Bisnis (Jakarta: Rajawali Pers, 2013), hlm. 78.

${ }^{21}$ Ibid., hlm. 49.

${ }^{22}$ Ibid., hlm. 51. 
Untuk mengetahui pengaruh variabel yang diteliti dilakukan analisis regresi berganda dengan uji signifikansi parsial (Uji t) dan uji signifikansi simultan (Uji F).

\section{HASIL PENELITIAN DAN PEMBAHASAN}

\section{Gambaran Umum Responden}

Pengambilan data primer pada penelitian menggunakan instrumen kuesioner yang disebar pada 11 ruangan di Jurusan Ekonomi Syariah yaitu pada mahasiswa semester VIII ruangan ES-1, ES-2, ES-3, ES-4, SE-5, dan ES-6, mahasiswa semester VI ruangan ES-1, ES-2, dan ES-3, serta mahasiswa semester IV ruangan ES-4 dan ES-5.

Kuesioner tersebut terdiri dari 3 bagian, yaitu variabel modal, skill, dan minat menjadi entrepreneur. Penyebaran dan pengumpulan angket untuk digunakan pada uji validitas dan reliabilitas, yang dilakukan pada hari Rabu tanggal 22 Maret 2017. Sedangkan penyebaran dan pengumpulan angket yang sesungguhnya dilakukan pada hari Jum`at tanggal 24 Maret 2017. Berikut ini tabel karakteristik responden berdasarkan gender dan semester:

Tabel 4.1

Karakteristik Responden

\begin{tabular}{|l|c|c|}
\hline \multicolumn{1}{|c|}{ Karakteristik } & N & Persentase (\%) \\
\hline Gender: & 14 & $15,91 \%$ \\
Laki-Laki & 74 & $84,09 \%$ \\
Perempuan & & \\
\hline Semester: & 40 & $45,45 \%$ \\
VIII (delapan) & 25 & $28,41 \%$ \\
VI (enam) & 23 & $26,14 \%$ \\
IV (empat) & 88 & $100 \%$ \\
\hline Total Responden & & \\
\hline
\end{tabular}

Sumber : Data primer yang diolah, 2017 
Berdasarkan tabel di atas, terlihat jumlah responden perempuan lebih banyak daripada responden laki-laki, dengan persentase sebesar 84,09\% untuk perempuan sedangkan untuk responden laki-laki sebesar 15,91\%. Jumlah responden yang berada di semester VIII lebih banyak dibanding dengan jumlah responden yang berada di semester VI dan semester IV.

Hal ini terjadi karena peneliti hanya mampu mengumpulkan angket sebanyak 40 responden dari angkatan 2013, 25 responden dari angkatan 2014 dan 23 responden dari angkatan 2015. Sebab pengambilan sampel dilakukan secara acak, siapa saja bisa menjadi responden yang dipilih oleh peneliti. Jadi, responden dalam penelitian ini tidak memenuhi semua ruangan Jurusan Ekonomi Syariah karena keterbatasan peneliti.

\section{Hasil Analisa Data}

\section{Uji Validitas dan Reliabilitas}

Peneliti telah menyebarkan kuesioner/angket kepada 88 responden yang dipilih secara acak oleh peneliti, untuk diolah pada uji validitas. Syarat agar butir soal disebut valid adalah apabila nilai $r_{\text {hitung }}>r_{\text {tabel }}$ dan apabila nilai $r_{\text {hitung }}<r_{\text {tabel }}$ maka butir soal disebut tidak valid. Nilai $r_{\text {tabel }}$ dapat diperoleh melalui df $($ degree of freedom $)=\mathrm{n}-2($ signifikan $10 \%, \mathrm{n}=\mathrm{jumlah}$ sampel).

Tabel 4.2

Variabel Modal

\begin{tabular}{|c|c|c|c|}
\hline $\begin{array}{l}\text { No. } \\
\text { Item } \\
\text { Soal }\end{array}$ & $\begin{array}{c}\text { Nilai } \\
\text { r-hitung }\end{array}$ & $\begin{array}{c}\text { Nilai } \\
\text { r-tabel }\end{array}$ & Keterangan \\
\hline 1 & 0,501 & \multirow{11}{*}{$\begin{array}{l}\text { Instrumen } \\
\text { dikatakan valid jika } \\
\mathrm{r} \text { hitung }>\mathrm{r} \text { tabel } \\
\text { dengan } \mathrm{n}=88 \text { pada } \\
\text { taraf singifikan } \\
10 \%, \quad \mathrm{n}-2=86 \\
\text { sehingga diperoleh } \\
\mathrm{r} \text { tabel } 0,177 \text { (lihat } \\
\text { pada lampiran) }\end{array}$} & Valid \\
\hline 2 & 0,121 & & Tidak Valid \\
\hline 3 & 0,350 & & Valid \\
\hline 4 & 0,342 & & Valid \\
\hline 5 & 0,601 & & Valid \\
\hline 6 & 0,455 & & Valid \\
\hline 7 & 0,398 & & Valid \\
\hline 8 & 0,587 & & Valid \\
\hline 9 & 0,614 & & Valid \\
\hline 10 & 0,399 & & Valid \\
\hline 11 & 0,569 & & Valid \\
\hline
\end{tabular}




\begin{tabular}{|l|l|l|l|}
\hline 12 & 0,254 & \multirow{5}{*}{} & Valid \\
\hline 13 & 0,444 & & Valid \\
\end{tabular}

Sumber: Data primer yang diolah pada SPSS Versi 22, 2017

Berdasarkan tabel tersebut, jumlah soal yang diuji untuk variabel modal adalah sebanyak 13 soal, dimana terdapat 12 soal yang valid (memiliki nilai $\mathrm{r}$ hitung $>\mathrm{r}$ tabel) dan terdapat 1 soal yang tidak valid (memiliki nilai $r$ hitung $<\mathrm{t}$ tabel).

Tabel 4.3

Variabel Skill

\begin{tabular}{|c|c|c|c|}
\hline $\begin{array}{c}\text { No. } \\
\text { Item } \\
\text { Soal }\end{array}$ & $\begin{array}{c}\text { Nilai } \\
\text { r-hitung }\end{array}$ & $\begin{array}{c}\text { Nilai } \\
\text { r-tabel }\end{array}$ & Keterangan \\
\hline 1 & 0,370 & \multirow{9}{*}{$\begin{array}{l}\text { Instrumen } \\
\text { dikatakan valid } \\
\text { jika r hitung > r } \\
\text { tabel dengan } \mathrm{n}=88 \\
\text { pada taraf sinifikan } \\
10 \%, \quad \mathrm{n}-2=86 \\
\text { sehingga diperoleh } \\
\mathrm{r} \text { tabel } 0,177 \text { (lihat } \\
\text { pada lampiran) }\end{array}$} & Valid \\
\hline 2 & 0,542 & & Valid \\
\hline 3 & 0,508 & & Valid \\
\hline 4 & 0,582 & & Valid \\
\hline 5 & 0,517 & & Valid \\
\hline 6 & 0,598 & & Valid \\
\hline 7 & 0,709 & & Valid \\
\hline 8 & 0,529 & & Valid \\
\hline 9 & 0,604 & & Valid \\
\hline
\end{tabular}

Sumber: Data primer yang diolah pada SPSS Versi 22, 2017

Berdasarkan tabel tersebut, jumlah soal yang diuji untuk variabel skill adalah sebanyak 9 soal, dimana terdapat pada semua soal dinyatakan valid (memiliki nilai $r$ hitung $>\mathrm{r}$ tabel).

Tabel 4.4

Variabel minat menjadi entrepreneur

\begin{tabular}{|c|c|c|c|}
\hline $\begin{array}{c}\text { No. } \\
\text { Item } \\
\text { Soal }\end{array}$ & $\begin{array}{c}\text { Nilai } \\
\text { r-hitung }\end{array}$ & $\begin{array}{c}\text { Nilai } \\
\text { r-tabel }\end{array}$ & Keterangan \\
\hline 1 & 0,564 & \multirow{7}{*}{$\begin{array}{l}\text { Instrumen } \\
\text { dikatakan valid } \\
\text { jika } r \text { hitung }>r \\
\text { tabel dengan } n=88 \\
\text { pada taraf sinifikan } \\
10 \%, \quad n-2=86\end{array}$} & Valid \\
\hline 2 & 0,453 & & Valid \\
\hline 3 & 0,556 & & Valid \\
\hline 4 & 0,494 & & Valid \\
\hline 5 & 0,573 & & Valid \\
\hline 6 & 0,627 & & Valid \\
\hline 7 & 0,575 & & Valid \\
\hline
\end{tabular}




\begin{tabular}{|c|c|c|c|}
\hline 8 & 0,595 & sehingga diperoleh & Valid \\
\hline 9 & 0,528 & $\begin{array}{l}\mathrm{r} \text { tabel } 0,177 \text { (lihat } \\
\text { pada lampiran) }\end{array}$ & Valid \\
\hline
\end{tabular}

Sumber: Data primer yang diolah pada SPSS Versi 22, 2017

Berdasarkan tabel tersebut, jumlah soal yang diuji untuk variabel modal adalah sebanyak 9 soal, dimana terdapat pada semua soal dinyatakan valid (memiliki nilai $r$ hitung $>\mathrm{r}$ tabel).

Berikut ini tabel rangkuman dari semua variabel yang diuji validitasnya:

Tabel 4.5

Hasil Pengujian Validitas Semua Variabel

\begin{tabular}{|l|c|c|c|}
\hline Variabel & $\begin{array}{c}\text { Jumlah } \\
\text { Butir Soal }\end{array}$ & $\begin{array}{c}\text { Jumlah Soal } \\
\text { Valid }\end{array}$ & $\begin{array}{c}\text { Jumlah Soal } \\
\text { Gugur }\end{array}$ \\
\hline Modal & 13 & 12 & 1 \\
\hline Skill & 9 & 9 & 0 \\
\hline $\begin{array}{l}\text { Minat Menjadi } \\
\text { Entrepreneur }\end{array}$ & 9 & 9 & 0 \\
\hline \multicolumn{1}{|c|}{ Total } & $\mathbf{3 1}$ & $\mathbf{3 0}$ & $\mathbf{1}$ \\
\hline
\end{tabular}

Sumber: Data primer yang diolah, 2017

Berdasarkan tabel di atas, menunjukkan bahwa pada variabel modal terdapat 13 butir soal, kemudian setelah dilakukan uji validitas, terdapat 1 soal yang tidak valid. Artinya hanya 12 butir soal yang dapat digunakan untuk pengolahan data selanjutnya. Pada variabel skill terdapat 9 butir soal, kemudian setelah dilakukan uji validitas, ternyata semua butir soal dinyatakan valid. Begitu juga dengan variabel minat menjadi entrepreneur terdapat 9 butir soal, kemudian dilakukan uji validitas, dan semua butir soal dinyatakan valid. Maka dari 31 soal terdapat 1 soal yang tidak valid/gugur, sedangkan untuk soal yang valid terdapat 30 butir soal.

Hasil uji reliabilitas didasarkan pada nilai Alpha Cronbach $(\alpha)$, menunjukkan semua variabel yang diteliti memenuhi unsur reliabilitas dengan nilai Alpha Cronbach $(\alpha)$ lebih besar dari 0,60. Berikut tabel hasil pengujian reliabilitas:

Tabel 4.6

\section{Hasil Uji Reliabilitas}




\begin{tabular}{|l|c|c|c|}
\hline \multicolumn{1}{|c|}{ Variabel } & Cronbach 's Alpha & Jumlah Item & Keterangan \\
\hline Modal & 0,677 & 12 & Reliabel \\
\hline Skill & 0,711 & 9 & Reliabel \\
\hline $\begin{array}{l}\text { Minat menjadi } \\
\text { Entrepreneur }\end{array}$ & 0,704 & 9 & Reliabel \\
\hline
\end{tabular}

Sumber: Data primer yang diolah pada SPSS Versi 22, 2017

\section{Uji Analisis Statistik Deskriptif}

Analisis statistik deskriptif digunakan untuk menggambarkan tentang data-data penelitian seperti mean, standar deviasi, modus, dan lain-lain. Dalam penelitian ini akan dilakukan analisis deskriptif dengan memberikan gambaran tentang jumlah data minimum, maksimal, mean, dan standar deviasi.

\section{Tabel 4.7}

\section{Hasil Output Descriptive Statistics}

Descriptive Statistics

\begin{tabular}{|l|r|r|r|r|r|}
\hline & N & Minimum & Maximum & Mean & Std. Deviation \\
\hline minat_entrepreneur & 88 & 28 & 45 & 37.44 & 2.959 \\
Modal & 88 & 31 & 45 & 38.35 & 3.096 \\
Skill & 88 & 34 & 59 & 49.31 & 3.987 \\
Valid N (listwise) & 88 & & & & \\
\hline
\end{tabular}

Sumber: Data Primer yang diolah pada SPSS Versi 22, 2017

Berdasarkan tabel di atas, dapat dilihat bahwa variabel minat menjadi entrepreneur dengan jumlah data $(\mathrm{N})$ sebanyak 88 mempunyai minat menjadi entrepreneur rata-rata 38,35; dengan minat menjadi entrepreneur minimal 31 dan maksimal 45; sedangkan standar deviasinya 3,096. Variabel modal dengan jumlah data $(\mathrm{N})$ sebanyak 88 mempunyai modal rata-rata 49,31; dengan modal minimal 34 dan maksimal 59; sedangkan standar deviasinya 3,987. Variabel skill dengan jumlah data (N) sebanyak 88 mempunyai skill rata-rata 37,44; dengan skill minimal 28 dan maksimal 45; sedangkan standar deviasinya 2,959 . 


\section{Uji Normalitas}

Tabel 4.8

Hasil Output Uji Normalitas One-Sample Kolmogorov Smirnov

One-Sample Kolmogorov-Smirnov Test

\begin{tabular}{|c|c|c|c|c|}
\hline & & minat_entrepreneur & Modal & Skill \\
\hline \multicolumn{2}{|l|}{$\mathrm{N}$} & 88 & 88 & 88 \\
\hline Normal & Mean & 49.31 & 37.44 & 38.35 \\
\hline Parameters ${ }^{a, b}$ & Std. Deviation & 3.987 & 2.959 & 3.096 \\
\hline Most Extreme & Absolute & .101 & .131 & .102 \\
\hline \multirow[t]{2}{*}{ Differences } & Positive & .101 & .128 & .081 \\
\hline & Negative & -.087 & -.131 & -.102 \\
\hline \multicolumn{2}{|l|}{ Test Statistic } & .101 & .131 & .102 \\
\hline \multicolumn{2}{|c|}{ Asymp. Sig. (2-tailed) } & $.026^{c}$ & $.001^{c}$ & $.023^{c}$ \\
\hline
\end{tabular}

a. Test distribution is Normal.

b. Calculated from data.

c. Lilliefors Significance Correction.

Uji normalitas digunakan untuk melihat apakah data yang dipakai berdistribusi normal atau tidak. Data disebut berdistribusi normal jika nilai signifikansi $\geq 0,1$ dan data disebut tidak berdistribusi normal jika nilai signifikansi _. 0,1. Untuk nilai signifikansi dapat diambil dari nilai Absolute maupun Test Statistic. Berdasarkan output data di atas, diperoleh nilai Absolute maupun Test Statistic setiap variabel nilai $\operatorname{sig} \geq 0,1$, yaitu modal $=$ $0,101 \geq 0,1 ;$ Skill $=0,131 \geq 0,1 ;$ dan minat menjadi entrepreneur $=0,102 \geq$ 0,1 . Maka dapat disimpulkan bahwa semua variabel pada penelitian ini berdistribusi normal.

\section{Uji Linearitas}

Tabel 4.9

Hasil Output Uji Linearitas

ANOVA Table

\begin{tabular}{|ll|r|r|r|r|r|}
\hline & $\begin{array}{r}\text { Sum of } \\
\text { Squares }\end{array}$ & df & \multicolumn{1}{c|}{ Sean } & & \\
\hline minat__ Between Groups & F & Sig. \\
entrep & Linearity & 225.577 & 1 & 225.577 & 31.580 & .000 \\
\hline
\end{tabular}




\begin{tabular}{|ll|r|r|r|r|r|}
\hline \multirow{2}{*}{$\begin{array}{l}\text { reneur } \\
\text { modal }\end{array}$} & $\begin{array}{c}\text { Deviation } \\
\text { from Linearity }\end{array}$ & 101.344 & 15 & 6.756 & .946 & .520 \\
\cline { 2 - 7 } & Within Groups & 507.159 & 71 & 7.143 & & \\
\cline { 2 - 7 } & Total & 834.080 & 87 & & & \\
\hline
\end{tabular}

Sumber: Data primer yang diolah pada SPSS Versi 22, 2017

ANOVA Table

\begin{tabular}{|c|c|c|c|c|c|c|c|}
\hline & & & $\begin{array}{l}\text { Sum of } \\
\text { Squares }\end{array}$ & $d f$ & $\begin{array}{l}\text { Mean } \\
\text { Square }\end{array}$ & $\mathrm{F}$ & Sig. \\
\hline \multirow{5}{*}{$\begin{array}{l}\text { minat_- } \\
\text { entrep } \\
\text { reneur } \\
{ }^{*} \text { skill }\end{array}$} & Between Groups & (Combined) & 367.726 & 14 & 26.266 & 4.112 & .000 \\
\hline & & Linearity & 274.496 & 1 & 274.496 & 42.986 & .000 \\
\hline & & $\begin{array}{l}\text { Deviation } \\
\text { from Linearity }\end{array}$ & 93.230 & 13 & 7.172 & 1.123 & .355 \\
\hline & Within Groups & & 466.354 & 73 & 6.388 & & \\
\hline & Total & & 834.080 & 87 & & & \\
\hline
\end{tabular}

Sumber: Data primer yang diolah pada SPSS Versi 22, 2017

Dari tabel ANOVA di atas memaparkan uji kelinearan, yang menunjukkan bahwa nilai $F_{\text {hitung }}$ sebesar 31,580 dan 42,986. Sedangkan untuk nilai $F_{\text {tabel }}(2: 85: 0,1)$ adalah sebesar 2,366. Diketahui bahwa jika nilai $F_{\text {hitung }}>\mathrm{F}_{\text {tabel}}$, maka terdapat kelinearan. Maka dari tabel di atas dapat disimpulkan bahwa data yang digunakan adalah linear, sebab $F_{\text {hitung }}$ $(31,580)>F_{\text {tabel }}(2,366)$ atau $F_{\text {hitung }}(42,986)>F_{\text {tabel }}(2,366)$.

\section{Uji Asumsi Klasik}

\section{a) Uji Multikolinearitas}

Model regresi yang baik seharusnya tidak terjadi gejala multikolinearitas dan untuk mengetahui ada atau tidaknya gejala tersebut, dilihat dari nilai Tolerance dan Variance Inflation Factor (VIF), apabila nilai VIF kurang dari 10 dan Tolerance lebih dari 0,1, maka dinyatakan tidak terjadi gejala multikolinearitas. 
Tabel 4.10

\section{Hasil Output Uji Multikolinearitas}

Coefficients $^{\mathrm{a}}$

\begin{tabular}{|c|c|c|c|c|c|c|c|}
\hline \multirow[b]{2}{*}{ Model } & \multicolumn{2}{|c|}{$\begin{array}{l}\text { Unstandardized } \\
\text { Coefficients }\end{array}$} & $\begin{array}{l}\text { Standardized } \\
\text { Coefficients }\end{array}$ & \multirow[b]{2}{*}{$\mathrm{t}$} & \multirow[b]{2}{*}{ Sig. } & \multicolumn{2}{|c|}{$\begin{array}{l}\text { Collinearity } \\
\text { Statistics }\end{array}$} \\
\hline & B & Std. Error & Beta & & & $\begin{array}{c}\text { Tolera } \\
\text { nce }\end{array}$ & VIF \\
\hline 1 (Constant) & 9.249 & 3.780 & & 2.447 & .016 & & \\
\hline Modal & .253 & .073 & .376 & 3.483 & .001 & .790 & 1.265 \\
\hline Skill & .444 & .098 & .425 & 4.541 & .000 & .790 & 1.265 \\
\hline
\end{tabular}

a. Dependent Variable: minat_entrepreneur

Berdasarkan hasil output di atas, dapat diketahui bahwa nilai Tolerance lebih besar dari 0,10 yaitu 0,790>0,10 dan nilai VIF lebih kecil dari 10,00 yaitu $1,265<10,00$. Maka dapat disimpulkan bahwa tidak terjadi gejala multikolinearitas.

\section{b) Uji Heterokedastisitas}

Jika nilai Signifikansi lebih kecil dari 0,1 maka terjadi heterokedastisitas, namun jika nilai Signifikansi lebih besar dari 0,1 maka tidak terjadi heterokedastisitas. Pada penelitian ini uji heterokedastisitas dilakukan dengan Uji Glejser, ditunjukkan pada tabel di bawah ini, bahwa nilai korelasi kedua variabel independen dengan nilai signifikansi lebih besar dari 0,1, yaitu 0,461 >0,1 atau 0,719>0,1. Maka dapat disimpulkan bahwa tidak terjadi masalah heterokedastisitas.

Tabel 4.11

\section{Hasil Output Uji Heterokedastisitas}

Coefficients $^{\mathrm{a}}$

\begin{tabular}{|c|c|c|c|c|c|c|c|}
\hline \multirow[b]{2}{*}{ Model } & \multicolumn{2}{|c|}{$\begin{array}{c}\text { Unstandardized } \\
\text { Coefficients }\end{array}$} & \multirow{2}{*}{$\begin{array}{c}\text { Standardized } \\
\text { Coefficients }\end{array}$} & \multirow[b]{2}{*}{$\mathrm{T}$} & \multirow[b]{2}{*}{ Sig. } & \multicolumn{2}{|c|}{$\begin{array}{l}\text { Collinearity } \\
\text { Statistics }\end{array}$} \\
\hline & $B$ & Std. Error & & & & Tolerance & VIF \\
\hline (Constant) & 4.210 & 2.177 & & 1.934 & .056 & & \\
\hline Modal & -.031 & .042 & -.090 & -.740 & .461 & .790 & 1.265 \\
\hline Skill & -.020 & .056 & -.044 & -.361 & .719 & .790 & 1.265 \\
\hline
\end{tabular}




\section{Koefisien Determinasi ( $R$ Square)}

Tabel 4.12

Hasil Output Uji Koefisien Determinasi ( $R$ Square)

Model Summaryb

\begin{tabular}{|l|c|r|r|r|}
\hline Model & $\mathrm{R}$ & $\mathrm{R}$ Square & Adjusted R Square & Std. Error of the Estimate \\
\hline 1 & $.643^{\mathrm{a}}$ & .413 & .399 & 2.400 \\
\hline
\end{tabular}

a. Predictors: (Constant), skill, modal

b. Dependent Variable: minat_entrepreneur

Berdasarkan tabel di atas diketahui bahwa besarnya $R$ Square adalah 0,413 atau sama dengan 41,3\%. Artinya bahwa variasi variabel Modal dan Skill dapat menjelaskan variasi variabel Minat menjadi Entrepreneur sebesar 41,3\%. Sedangkan sisanya 58,7\% (100\% - 41,3\%) dijelaskan oleh variabel-variabel lain yang tidak menjadi fokus penelitian.

Adapun Standar Error of the Estimate sebesar 2,400. Jika dilihat dalam analisis deskriptif statistik bahwa standar deviasi modal adalah 3,987 yang jauh lebih besar dari Standard Error (3,987 > 2,400). Menunjukkan bahwa model regresi sangat bagus bertindak sebagai prediktor Minat menjadi Entrepreneur.

\section{Uji Analisis Regresi Linear Berganda}

Tabel 4.13

Hasil Output Uji Analisis Regresi Linear Berganda

Coefficients $^{\mathrm{a}}$

\begin{tabular}{|c|c|c|c|c|c|c|}
\hline \multirow{2}{*}{\multicolumn{2}{|c|}{ Model }} & \multicolumn{2}{|c|}{ Unstandardized Coefficients } & \multirow{2}{*}{$\begin{array}{c}\text { Standardized } \\
\text { Coefficients } \\
\text { Beta }\end{array}$} & \multirow[b]{2}{*}{$t$} & \multirow[b]{2}{*}{ Sig. } \\
\hline & & $B$ & Std. Error & & & \\
\hline \multirow[t]{3}{*}{1} & (Constant) & 9.249 & 3.780 & & 2.447 & .016 \\
\hline & Modal & .253 & .073 & .326 & 3.483 & .001 \\
\hline & Skill & .444 & .098 & .425 & 4.541 & .000 \\
\hline
\end{tabular}

a. Dependent Variable: minat_entrepreneur 
Persamaan regresi linear berganda dengan 2 variabel independen. Nilai-nilai pada output dimasukkan ke dalam persamaan regresi linear berganda sebagai berikut:

$$
\mathrm{ME}=9,249+0,253 \mathrm{M}+0,444 \mathrm{~S}
$$

Artinya :

1) Nilai konstanta (a) adalah 9,249. Dapat diartikan apabila modal dan skill nilainya adalah 0 maka minat menjadi entrepreneur nilainya 9,249 satuan.

2) Nilai koefisien regresi variabel modal $\left(b_{1}\right)$ bernilai positif yaitu 0,253. Dapat diartikan bahwa setiap peningkatan modal sebesar 1 satuan, maka akan meningkatkan minat menjadi entrepreneur sebesar 0,253 satuan dengan asumsi variabel independen lain nilainya tetap.

3) Nilai koefisien regresi variabel skill $\left(\mathrm{b}_{2}\right)$ bernilai positif yaitu 0,444 . Dapat diartikan bahwa setiap peningkatan skill sebesar 1 satuan, maka akan meningkatkan minat menjadi entrepreneur sebesar 0,444 satuan dengan asumsi variabel independen lain nilainya tetap.

\section{Uji Hipotesis}

\section{a) Uji Signifikan Parsial (Uji t)}

Tabel 4.14

\section{Hasil Output Uji t}

Coefficients $^{a}$

\begin{tabular}{|c|c|c|c|c|c|}
\hline \multirow[b]{2}{*}{ Model } & \multicolumn{2}{|c|}{$\begin{array}{c}\text { Unstandardized } \\
\text { Coefficients }\end{array}$} & \multirow{2}{*}{$\begin{array}{c}\begin{array}{c}\text { Standardized } \\
\text { Coefficients }\end{array} \\
\text { Beta }\end{array}$} & \multirow[b]{2}{*}{$\mathrm{T}$} & \multirow[b]{2}{*}{ Sig. } \\
\hline & $B$ & Std. Error & & & \\
\hline $1 \quad$ (Constant) & 9.249 & 3.780 & & 2.447 & .016 \\
\hline Modal & .253 & .073 & .326 & 3.483 & .001 \\
\hline Skill & .444 & .098 & .425 & 4.541 & .000 \\
\hline
\end{tabular}

a. Dependent Variable: minat_entrepreneur 
$\mathrm{T}_{\text {hitung }}$ adalah pengujian signifikansi untuk mengetahui pengaruh variabel $\mathrm{X}_{1}$ dan $\mathrm{X}_{2}$ terhadap $\mathrm{Y}$ secara parsial. Kriteria pengujian adalah:

$\mathrm{Jika}-\mathrm{t}_{\text {tabel }} \leq \mathrm{t}_{\text {hitung }} \leq \mathrm{t}_{\text {tabel }}$ maka $\mathrm{H}_{0}$ diterima dan $\mathrm{H}_{\mathrm{a}}$ ditolak.

$\mathrm{Jika}-\mathrm{t}_{\text {hitung }} \leq \mathrm{t}_{\text {tabel }}$ atau $\mathrm{t}_{\text {hitung }}>\mathrm{t}_{\text {tabel }}$ maka $\mathrm{H}_{0}$ ditolak dan $\mathrm{H}_{\mathrm{a}}$ diterima. Sedangkan kriteria pengujian berdasarkan nilai signifikansi adalah:

Jika signifikansi > 0,1 maka $\mathrm{H}_{0}$ diterima dan $\mathrm{H}_{\mathrm{a}}$ ditolak.

Jika signifikansi $<0,1$ maka $\mathrm{H}_{0}$ ditolak dan $\mathrm{H}_{\mathrm{a}}$ diterima.

1) Pengujian koefisien variabel modal $\left(b_{1}\right)$

Hipotesis:

$\mathrm{H}_{0}$ 1: Tidak Terdapat pengaruh modal terhadap minat mahasiswa menjadi entrepreneur.

$\mathrm{H}_{\mathrm{a}} 1$ : Terdapat pengaruh modal terhadap minat mahasiswa menjadi entrepreneur.

Dari output dapat diperoleh thitung sebesar 3,483 dan nilai signifikansinya 0,001 . Maka nilai $t_{\text {hitung }} 3,483>t_{\text {tabel }} 1,663$ dan nilai signifikansi $<0,1$, sehingga $\mathrm{H}_{0}$ ditolak. Jadi, dapat disimpulkan bahwa terdapat pengaruh modal terhadap minat mahasiswa menjadi entrepreneur. 2) Pengujian koefisien variabel skill $\left(\mathrm{b}_{2}\right)$

Hipotesis:

$\mathrm{H}_{0} 2$ : Tidak terdapat pengaruh skill terhadap minat mahasiswa menjadi entrepreneur.

$\mathrm{H}_{\mathrm{a}} 2$ : Terdapat pengaruh skill terhadap minat mahasiswa menjadi entrepreneur.

Dari output dapat diperoleh $\mathrm{t}_{\text {hitung }}$ sebesar 4,541 dan nilai signifikansinya 0,000. Maka nilai $t_{\text {hitung }} 4,541>t_{\text {tabel }} 1,663$ nilai sinifikansi $<0,1$, sehingga $\mathrm{H}_{0}$ ditolak. Jadi, dapat disimpulkan bahwa terdapat pengaruh skill terhadap minat mahasiswa menjadi entrepreneur. 
b) Uji Signifikansi Simultan (Uji F)

Tabel 4.15

\section{Hasil Output Uji F}

ANOVA $^{a}$

\begin{tabular}{|rl|r|r|r|r|r|}
\hline Model & & \multicolumn{1}{c|}{$\begin{array}{c}\text { Sum of } \\
\text { Squares }\end{array}$} & Df & \multicolumn{1}{c|}{$\begin{array}{c}\text { Sean } \\
\text { Square }\end{array}$} & F & Sig. \\
\hline 1 & Regression & 344.376 & 2 & 172.188 & 29.887 & $.000^{\mathrm{b}}$ \\
& Residual & 489.704 & 85 & 5.761 & & \\
& Total & 834.080 & 87 & & & \\
& & & & & & \\
& & &
\end{tabular}

a. Dependent Variable: minat_entrepreneur

b. Predictors: (Constant), skill, modal

ANOVA atau analisis varians, yaitu uji regresi secara bersamasama (uji F) untuk menguji pengaruh beberapa variabel independen terhadap variabel dependen. Pengujian ini menggunakan tingkat signifikansi 0,1. Berdasarkan output di atas, diperoleh $\mathrm{F}_{\text {hitung }}$ sebesar 29,887. Sedangkan nilai $F_{\text {tabel }}$ sebesar 2,366.

Kriteria Pengujian:

Jika $\mathrm{F}_{\text {hitung }}<\mathrm{F}_{\text {tabel }}$ maka $\mathrm{H}_{0}$ diterima dan $\mathrm{H}_{\mathrm{a}}$ ditolak.

Jika $\mathrm{F}_{\text {hitung }}>\mathrm{F}_{\text {tabel }}$ maka $\mathrm{H}_{0}$ ditolak dan $\mathrm{H}_{\mathrm{a}}$ diterima.

Maka $F_{\text {hitung }}>\mathrm{F}_{\text {tabel }}(29,887>2,366)$, sehingga $\mathrm{H}_{0}$ ditolak dan dapat disimpulkan bahwa modal dan skill secara bersama-sama (simultan) berpengaruh terhadap minat mahasiswa menjadi entrepreneur. $\mathrm{F}_{\text {tabel }}$ dapat dilihat pada lampiran.

\section{Pembahasan Hasil Analisis Data}

Penelitian ini bertujuan untuk mengetahui terdapat atau tidak terdapat pengaruh modal $\left(\mathrm{X}_{1}\right)$ dan skill $\left(\mathrm{X}_{2}\right)$ terhadap minat mahasiswa menjadi entrepreneur (Y) pada Mahasiswa Jurusan Ekonomi Syariah IAIN Padangsidimpuan.

Hasil penelitian pada variabel modal $\left(\mathrm{X}_{1}\right)$ terhadap minat mahasiswa menjadi entrepreneur, memiliki nilai rata-rata sebesar 49,31, standar deviasi sebesar 3,978, nilai maksimum sebanyak 59 dan nilai minimum sebanyak 34 
dengan jumlah data $(\mathrm{N})$ sebanyak 88 orang, diperoleh nilai koefisien regresi $\mathrm{M}$ sebesar 0,253 satuan yang menyatakan bahwa setiap kenaikan modal sebesar 1 satuan akan meningkatkan minat mahasiswa menjadi entrepreneur sebesar 0,253 satuan dengan asumsi variabel independen lain nilainya tetap, dan diperoleh thitung sebesar 3,483 serta nilai signifikansi 0,001 yang berarti nilai siginifikan $\leq 0,1$ sehingga $\mathrm{H}_{0}$ ditolak. Maka dapat disimpulkan bahwa modal berpengaruh positif terhadap minat mahasiswa menjadi entrepreneur, artinya jika modal meningkat maka minat mahasiswa menjadi entrepreneur akan meningkat. Total nilai kuesioner pada variabel ini sebesar 4339, total ini paling banyak diantara variabel lain. Hal ini berarti variabel modal memberikan kontribusi yang paling besar.

Hasil penelitian pada variabel skill $\left(\mathrm{X}_{2}\right)$ terhadap minat mahasiswa menjadi entrepreneur, memiliki nilai rata-rata sebesar 37,44, standar deviasi sebesar 2,959, nilai maksimum sebanyak 45 dan nilai minimum sebanyak 28 dengan jumlah data $(\mathrm{N})$ sebanyak 88 orang, diperoleh nilai koefisien regresi $\mathrm{S}$ sebesar 0,444 satuan yang menyatakan bahwa setiap kenaikan skill sebesar 1 satuan akan meningkatkan minat mahasiswa menjadi entrepreneur sebesar 0,444 satuan dengan asumsi variabel independen lain nilainya tetap, dan diperoleh thitung sebesar 4,541 serta nilai signifikansi 0,000 yang berarti nilai siginifikan $\leq 0,1$ sehingga $\mathrm{H}_{0}$ ditolak. Maka dapat disimpulkan bahwa skill berpengaruh positif terhadap minat mahasiswa menjadi entrepreneur, artinya jika skill meningkat maka minat mahasiswa menjadi entrepreneur akan meningkat. Total nilai kuesioner pada variabel ini sebesar 3295, total ini paling sedikit dari semua variabel yang diteliti. Hal ini disebabkan jumlah jawaban responden lebih sedikit pointnya dibanding variabel modal dan minat menjadi entrepreneur.

Berdasarkan hasil uji secara simultan (uji F), diperoleh nilai $F_{\text {hitung }}>$ $\mathrm{F}_{\text {tabel }}(29,887>2,366)$ sehingga $\mathrm{H}_{0}$ ditolak, artinya terdapat pengaruh antara variabel modal dan skill terhadap minat mahasiswa menjadi entrepreneur. Nilai signifikansi uji F untuk variabel modal dan variabel skill sebesar 0,000 yang mengindikasikan bahwa terdapat pengaruh positif terhadap minat 
mahasiswa menjadi entrepreneur pada Jurusan Ekonomi IAIN Padangsidimpuan. Total nilai kuesioner pada variabel ini sebesar 3375.

Adanya minat menjadi entrepreneur disebabkan karena adanya suatu motif, yaitu motif berprestasi, dan seorang wirausaha akan berhasil apabila memiliki kemauan dan kemampuan, karena kemauan dan kemampuan sangat dipengaruhi oleh pengetahuan dan pengalaman. Jadi, kemauan, kemampuan, dan pengetahuan merupakan modal dasar dalam kewirausahaan serta memiliki keterampilan dan kreativitas dalan berwirausaha. Penelitian ini membuktikan teori yang dikemukakan Muh. Yunus bahwa menjadi wirausaha pertama-tama yang harus dimiliki adalah modal dasar berupa ide atau visi yang jelas, kemauan dan komitmen yang kuat, cukup modal baik uang maupun waktu, cukup tenaga dan pikiran. Sedangkan Alma menyatakan bahwa makin banyak keterampilan yang di kuasai, makin tinggi minat bisnisnya dan makin banyak peluang terbuka untuk membuka wirausaha.

Penelitian ini masih memiliki banyak keterbatasan, diantaranya:

1) Minat menjadi entrepreneur yang dibahas pada penelitian ini adalah kenyataan yang terlihat pada bentuk pernyataan dan sikap secara alamiah dari mahasiswa, bukan hanya bentuk kemauan atau keinginan semata, jadi untuk mengukur minat mahasiswa menjadi entrepreneur diukur dari kegiatannya dalam berwirausaha.

2) Hasil dari penelitian ini menunjukkan bahwa selain variabel modal dan skill terdapat variabel lain yang dapat mempengaruhi minat mahasiswa menjadi entrepreneur. Modal dan skill memberikan sumbangan sebesar 41,3\% terhadap minat mahasiswa menjadi entrepreneur, sedangkan 58,7\% lainnya dijelaskan oleh variabel lain yang tidak diteliti pada penelitian ini.

3) Variabel dalam penelitian ini hanya mencakup modal dan skill yang hanya mampu membuktikan $41,3 \%$ faktor-faktor yang mempengaruhi minat mahasiswa menjadi entrepreneur, maka penelitian ini seharusnya menambah variabel lain sehingga hasil penelitian ini lebih baik. 


\section{KESIMPULAN DAN SARAN}

\section{Kesimpulan}

Hasil penelitian dan pembahasan menunjukkan bahwa data yang diolah dalam penelitian ini adalah data yang berdistribusi normal serta linear sehingga dapat dilanjut untuk pengujian asumsi klasik, korelasi dan analisis regresi linear berganda yang hasilnya menunjukkan bahwa:

1. Ada pengaruh faktor modal terhadap minat mahasiswa menjadi entrepreneur pada Jurusan Ekonomi Syariah IAIN Padangsidimpuan sebesar $25,3 \%$.

2. Ada pengaruh faktor skill terhadap minat mahasiswa menjadi entrepreneur pada Jurusan Ekonomi Syariah IAIN Padangsidimpuan sebesar 44,4\%.

3. Faktor modal dan faktor skill secara simultan berpengaruh terhadap minat mahasiswa menjadi entrepreneur pada Jurusan Ekonomi Syariah IAIN Padangsidimpuan, yang ditunjukkan oleh nilai $F_{\text {hitung }}$ lebih besar dari $F_{\text {tabel }}$ yaitu sebesar 29,887 > 2,366. Kontribusi secara bersama-sama dari Faktor modal dan faktor skill adalah sebesar 41,3\% (R square) sedangkan 58,7\% dipengaruhi faktor lain.

\section{Saran}

1. Bagi lembaga sebagai tempat penelitian, peneliti menyarankan untuk lebih memperbanyak kegiatan yang berhubungan dengan mata kuliah Kewirausahaan, Bisnis Plan ataupun Studi Kelayakan Bisnis seperti yang telah dilaksanakan di Fakultas Ekonomi dan Bisnis Islam yaitu kegiatan Entrepreneurship day`s untuk menambah pengetahuan dalam bidang bisnis yang berorientasi kepada kewirausahaan dan mengembangkan keterampilan serta keahlian yang dimiliki seorang mahasiswa dalam berwirausaha.

2. Skill sebagai faktor yang diteliti peneliti untuk mempengaruhi minat mahasiswa menjadi entrepreneur ternyata mempunyai pengaruh yang sangat besar apabila dibandingkan dengan faktor modalnya, untuk itu peneliti menyarankan kepada lembaga untuk mengadakan suatu kegiatan 
yang dapat menumbuhkembangkan skill, yang dimaksud peneliti skill dalam penelitian ini berkaitan dengan keahlian, keterampilan dan kreativitas agar mahasiswa terbantu dalam menemukan serta menciptakan ide kreatif dan inovatif sebagai jalan untuk berwirausaha.

3. Bagi peneliti, disarankan untuk memperbanyak faktor dan sampel pada penelitian, karena kenyataannya banyak faktor pendorong berwirausaha dan bukan mahasiswa Jurusan Ekonomi Syariah IAIN Padangsidimpuan saja yang melakukan kegiatan wirausaha, namun masih banyak lagi mahasiswa dari Jurusan dan Fakultas lain yang melakukan kegiatan wirausaha. 


\section{DAFTAR PUSTAKA}

Abdullah Li Am Ibnu Ibrahim, Konglomerat Sukses: Bagaimana Meraih dan Mengelola Kekayaan Menurut Tuntunan Islam, Jakarta: Zikrul Hakim, 2004.

Asmadi Alsa, Pendekatan Kuantitatif \& Kualitatif Serta Kombinasinya Dalam Penelitian Psikologi, Yogyakarta: Pustaka Pelajar, 2004.

Buchari Alma, Kewirausahaan, Bandung: Alfabeta, 2009.

Buku Pedoman Magang Jurusan Ekonomi Syariah \& Jurusan Perbankan Syariah, Visi dan Misi Fakultas Ekonomi dan Bisnis Islam Padangsidimpuan: FEBI IAIN Padangsidimpuan, 2016.

Data Akademik Jurusan Ekonomi Syariah Fakultas Ekonomi dan Bisnis Islam IAIN Padangsidimpuan

Departemen Agama RI, Al-Qur`an dan Terjemahnya, Semarang: PT. Karya Toha Putra, 1999.

Desi Anwar, Kamus Lengkap Bahasa Indonesia, Surabaya: Amelia, 2003.

Husein Umar, Metode Penelitian untuk Skripsi dan Tesis Bisnis, Jakarta: Rajawali Pers, 2013.

J Winardi, Entrepreneur \& Entrepreneurship, Jakarta: Kencana Prenadamedia Group, 2003.

Kasmir, Kewirausahaan, Jakarta: Rajawali Pers, 2013.

Muh.Yunus, Islam dan Kewirausahaan Inovatif, Malang: UIN-Malang Press, 2008.

Netti Tinaprilla, Jadi Kaya dengan Berbisnis di Rumah, Jakarta: PT. Elex Media Komputindo, 2007.

Suryana, Kewirausahaan, Jakarta: Salemba Empat, 2010.

, Kewirausahaan Kiat dan Proses Menuju Sukses, Jakarta: Salemba Empat, 2013.

http://www.republika.co.id, di akses pada hari Senin tanggal 21 Maret 2017 pukul 16.00 WIB. 